\title{
Satisfaction of Supplementary Insurance and Medical Services during Trips in War Survivors and their Families
}

\author{
Mohammadreza Soroush ${ }^{1}$, Batool Mousavi ${ }^{2}$, Farzaneh Maftoon ${ }^{3, *}$, Kazem Mohammad ${ }^{4}$, Zohreh Ganjparvar ${ }^{1}$ \\ ${ }^{1}$ Janbazan Medical and Engineering Research Center (JMERC), Tehran, Iran \\ ${ }^{2}$ Prevention Department, Janbazan Medical and Engineering Research Center (JMERC), Tehran, Iran \\ ${ }^{3}$ Health Services Management Group of Health Metrics Research Center, Iranian Institute for Health Sciences Research, ACECR, Tehran, \\ Iran \\ ${ }^{4}$ Epidemiology and Statistical Department, Health Faculty, Tehran University of Medical Sciences, Tehran, Iran
}

*Corresponding Author: Farzaneh Maftoon, MD, Health Services Management Group of Health Metrics Research Center, Iranian Institute for Health Sciences Research, ACECR, Iran. Tel: +98-9123262644, Email: fmaftoon5@ gmail.com

\begin{abstract}
Introduction: During trips the imposed costs are aggravated due to time and financial limits, not being familiar with treatment centers that are covered by the insurances and charges for accommodation. Insurance, especially supplementary treatment services insurance can be an appropriate solution to decrease these costs. These kinds of insurances cover a range of services including outpatient services to hospitalization and even sometimes unlimited services. The purpose of this study was to evaluate the satisfaction of war survivors and their families under the cover of supplementary insurance from medical care during trips.

Methods: This study was cross -sectional descriptive. The size of studied population was 77 people from war survivors and their families who were assessed by a provided questionnaire in 2015. The including criteria was war survivors and their families under the cover of Veterans and Martyrs Affair Foundation (VMAF) and supplementary insurance war survivors. The prepared questionnaire included two sections; the first section was included the personal indications and the second section included satisfaction evaluations.

Results: The prevalence of using medical care during trips in war survivors and their families was $2.72 \%$ and using medical care with supplemental insurance in trips was $1.5 \%$. The obtained results from the questionnaires revealed that the highest satisfaction on medical care services and its distance belongs to the veterans' families with the mean of 4.57and 4.27, respectively. In the subject of taking back the costs, martyrs' families were the least satisfied with the mean of 2.17. A significant relationship was found between sex and distance of the medical care services in trips $(\mathrm{p}=0.046)$. Men had more satisfaction compared to women. Finally it can be mentioned that there was not a significant relationship between client group and distance of medical care services during trips $(\mathrm{p}=0.067)$.

Conclusion: According to the results, affording the costs and paying them back by the insurance company needs modifications.

Keywords: Travel, Insurance, Satisfaction, Medical Services
\end{abstract}

Article History: Received: 26 Mar. 2016; Accepted: 18 Apr. 2016; Online Published: 25 Jun. 2016

Cite this article as: Soroush M, Mousavi B, Maftoon F, Mohammad K, Ganjparvar Z. Satisfaction of Supplementary insurance and medical services during trips in war survivors and their families. Int J Travel Med Glob Health. 2016;4(2):65-8. doi: 10.20286/ijtmgh-04026

\section{Introduction}

Health is one of the most important priorities of the societies [1]. Based on the world health organization (WHO) definition it consists of not only lacking of disease and disabilities but having perfect physical, mental and social welfare [2]. Health and hygiene services have been developed through technology improvements leading to the facilitation of services by physicians and has gradually decreased the suffering from illnesses and recovery trend adversities of patients [4]. On the other hand, these developed services put more charges, therefore not being able to afford the expensive costs threatens the individuals' health in societies [5]. These conditions are much more complicated during trips. This is because during trips due to time and financial limits and also patients not being familiar with treatment centers that are covered by the insurances as well as more charges that are imposed for accommodation, the costs are aggravated $[6,7]$. It seems that insurance can be a proper solution to decrease these costs. However, insurance companies often cover one third of the primary costs. Supplementary treatment services insurance can be an appropriate solution for this dilemma [8, 9]. In Iran and many developing countries, these kinds of insurances cover a range of services including outpatient services to hospitalization and even sometimes unlimited services. Another benefit that private supplementary insurance companies have provided is that the patient has more alternatives for choosing treatment centers (private or governmental) as well as different kinds of treatment services [8].

The Iraq imposed war against the Islamic republic of Iran has left more than 700,000 martyrs and veterans so far. After 28 years, many of the veterans have passed away due to different kinds of injuries and the statistics are increasing [10]. Iran has taken policies in order to decrease the difficulties as well as improving the quality of life of the war survivors, one of which is covering the families of the martyrs and veterans including the father, mother, spouse and children under the supplementary insurance for all the costs of their treatments [11]. The quality of the services can be evaluate by the insured people's problems for receiving health and hygiene services, satisfaction of the services and also identification of a variety of medical services. The objective of the following study was to evaluate the satisfaction of martyrs and veterans and their families under the cover of supplementary insurance from outpatient services and hospitalizations during trips.

\section{Methods}

This study was cross-sectional descriptive that was carried out in during 2015. The studied population included the war survivors and their families who were assessed by the prepared questionnaire in 2015. The sample volume included 
77 participated in the study. Maximum error of $d=0.06$ and confidence interval of 0.95 were indicated. Subjects were selected randomly among eligible individuals. The including criteria consisted of the veterans and the families of the martyrs and veterans under the cover of Veterans and Martyrs Affair Foundation (VMAF) and treatment supplementary insurance and veterans whom their primary information was available in the VMAF data bank. The questionnaires were obtained from the subjects who had returned from their trips and had used medical care services including outpatient visit or hospitalization during their vacation.

The prepared questionnaire included two sections. The first section included personal indications including sex, age, relativity, occupation, education and using supplementary insurance. The second section included the satisfaction of supplementary insurance services. This questionnaire was prepared in two phases. Qualitative studies were done by experts and then the pilot questionnaire of the field was prepared. Finalizing the questionnaire was done under the supervision of experts via examining it in the field by the experts. For assessing the reliability, the internal consistency coefficient (Cronbach's alpha) of the questionnaire was 0.84 . Then, a guideline was provided in the final step. After this phase and gathering an appropriate range of answers, in the second phase the final questionnaire was provided. This questionnaire included satisfaction in 3 sections: received services, distance to the place of delivering medical services and repayment. In each field the satisfaction index was quantified with marks from 1 to 5 by the questioned subjects. Ethics included describing the study for the subjects by the researchers primarily and assuring them that their information remained classified, no names were needed and the participation was due to their personal desire.

The questionnaires were filled via telephone and two researchers called the population for data gathering. Among the 2828 gathered data in this survey from 32 provinces, 77 cases reported using medical care in trips during the preceding year of the study. Gathered data was analyzed by SPSS version 21 software. In order to assess the variables of the study and the relations between them and the main variables based on the sort of the variable the regression test was applied. P-Value's less than 0.05 were considered as significant.

\section{Results}

The number of subjects who received medical care for outpatient visits or hospitalization during trips were 77 . The prevalence of using medical care during trips in war survivors and their families was $2.72 \%$ (77 out of 2828 cases) and using medical care with supplemental insurance in trips was $1.5 \%$ ( 45 out of 2828 subjects). The mean age of the participants were $54.8(\mathrm{SD}=21.5)$ from 3-94 years old. All the 77 cases reported that they had used their supplementary insurance during the preceding year of the study (Table 1).

All participants were under the cover of the supplementary insurance but $41.5 \%(n=32)$ did not used their supplementary insurance in order to get medical care during trips. They paid for their medical costs and did not proceed to get their expenses back. The most reasons for which they did not use their insurance were: not knowing they can use their supplementary insurance during trips (6 cases); bureaucracy ( 5 cases); their services not being under the cover of the supplementary insurance (4 cases); Lack of time and distances to centers were covered by the supplementary insurance and the rest did not report any specific reason for not using supplementary insurance during trips.

Among participants, $75 \%$ of them who used their supplementary insurance received their medical services in the medical centers that had contract with supplementary insurance company, and they had medical services for free. Twelve patients paid for their health costs and applied to get their costs back from supplementary insurance.

Based on the first part of the questionnaire, the demographic information of the participants was indicated. These are presented in the first table. Among the population, $40.2 \%(n=31)$ of participants were male and $14.3 \%(n=11)$ were living in rural areas.

Table 1. Demographic information of the participants

\begin{tabular}{lccc}
\hline Variables & Relativity & Number (\%) & Age \pm SD \\
\hline \multirow{3}{*}{ Martyrs } & Parents & $22(66.7 \%)$ & $74.09 \pm 9.55$ \\
& Spouse & $7(21.2 \%)$ & $60.25 \pm 15.18$ \\
& Children & $4(12.1 \%)$ & $29.25 \pm 6.4$ \\
& Veterans & $29(65.9 \%)$ & $47.17 \pm 10.03$ \\
\multirow{5}{*}{ Veterans } & Parents & - & - \\
& Spouse & $10(22.7 \%)$ & $43.7 \pm 6.48$ \\
& Children & $5(11.4 \%)$ & $14 \pm 8.27$ \\
\hline
\end{tabular}

The obtained results from the questionnaires revealed that veterans' families had the most satisfaction for medical services during trips with the mean of 4.57. The most satisfaction for the distance of medical care services referred to veterans' families with the mean of 4.27. In the subject of taking costs back, martyrs' families were the least satisfied with the mean of 2.17. The statistical F test revealed significant differences of the satisfaction mean marks among different services at the level of $\alpha=0.01$.

The statistical $F$ test revealed significant differences of the satisfaction mean marks among different services at the level of $\alpha=0.01$.

Three different factors of satisfaction were indicated for the subjects as they are presented in the Table 2. The mean of satisfaction for costs return for the veteran's families was maximum with the mark of 5 and the least satisfactory factor belonged to the return of costs for martyr families with the mark of 2.167 .

Table 2. Satisfaction of supplementary insurance in travel medical care

\begin{tabular}{lccc}
\hline & $\begin{array}{c}\text { Satisfaction of } \\
\text { the Service } \\
(\text { Mean } \pm \text { SD) }\end{array}$ & $\begin{array}{c}\text { Satisfaction of } \\
\text { Distance } \\
(\text { Mean } \pm \text { SD) }\end{array}$ & $\begin{array}{c}\text { Satisfaction of } \\
\text { the Costs Return } \\
(\text { Mean } \pm \text { SD) }\end{array}$ \\
\hline $\begin{array}{l}\text { Veterans } \\
\text { families }\end{array}$ & $4.567 \pm 1.083$ & $4.27 \pm 1.534$ & $5 \pm 0$ \\
\hline $\begin{array}{l}\text { Veterans } \\
\text { Martyrs }\end{array}$ & $4.276 \pm 1.065$ & $4.17 \pm 1.104$ & $2.417 \pm 1.686$ \\
families & $4.182 \pm 0.975$ & $3.52 \pm 1.564$ & $2.167 \pm 1.169$ \\
\hline F & 0.725 & 2.304 & 1.653 \\
\hline P value & 0.488 & 0.067 & 0.24 \\
\hline
\end{tabular}

A significant relationship was found between the sex and distance of the medical care services in travel $(\mathrm{p}=0.046)$. Men had more satisfaction compared to women. There was not a significant relationship between client group and distance of the medical care during trips $(\mathrm{p}=0.067)$.

\section{Discussion}

One of the satisfactory definitions is based on expectancy approach. Satisfaction is a subsequent of the person's experiences in compression with his/her expectations. Due to this fact, the difference between expectations and 
experiences is the origin of satisfaction [12]. On the other hand, satisfaction extremely depends on the instant of the indication and can differ at other times. Sometimes, short time patients' dissatisfaction is a sign for treatment system developments. The important factor is the long term dissatisfaction that should be avoided. [12, 13].

Evaluations have indicated that different countries, depending on their level of development and by emphasizing human rights have considered the public satisfaction of the health system. Each year hospitals and treatment centers that have tried hard to develop treatment system applications are identified in the US [14]. In the European countries the public satisfaction of the treatment systems are even more accentuated $[12,15]$. In Iran, the national client satisfactory system has not yet been organized and the actions are only locally applied to this subject. Thus the role of insurance companies in Iran is to financially support patients. According to the fact that treatment insurance service commitments only support one-fourth of the hospitalizations costs in privet hospitals, it is necessary that supplementary treatment insurances help patients with out of pocket charges.

Results have revealed that the studied population including the martyrs' families, veterans and their families who were under the cover of supplementary treatment insurance and had used medical care services during their trips, were totally satisfied with both mentioned services. This reveals that good actions have been done in this case and the taken policies have been positive. So there are many efforts to be taken in order to comfort the trend for the patients especially in taking back the hospitalization costs. The most satisfaction both in the service and in the cost sections were referred to hospitalization which was satisfactory in comparison with the other developing countries [16, 17]. Meanwhile it seems that the distance that the families must go to receive their desired services is not very appropriate especially for the martyr families. This is why adequate constructions might help as new and efficient clinical centers. These presented services by these centers are more likely to be under the cover of supplementary insurance in order to provide better services.

Men were more satisfied compared to the women in this study. Gender might affect the level of medical care satisfaction but evidence for gender differences satisfaction levels is mixed [18]. Some studies report an evidence that men are less satisfied with the received medical care than women [19], and some report that women are more dissatisfied from medical care than men [20]. A metaanalysis of patient satisfaction concludes that there is no average gender difference in satisfaction with medical care [21].

Higher educated subjects have more expectations from the health system. Dissatisfaction among this group is totally natural because they are aware of the health care situation in developed countries and they are always comparing the present situation with what they know about developed countries [22, 23]. Despite these dissatisfactions, this can both be advantageous and disadvantageous for the future career of the country. If they take benefits of the expectations they can take wise and better policies in order to improve healthcare systems and facilitate the services both for the patients and insurance companies.

Although all the participants were under the cover of the supplementary insurance, but less than half of them paid to get medical care during their trip, without proceeding their expenses back. The General awareness of supplementary insurance facilities in the target population was weak. This situation is in direct relation with the improvement of the presented services and the quality of the treatments which could be developed by announcements and advertisements by both the VMAF and the insurance company.

\section{Conclusion}

The satisfaction of war survivors and their families who are under the cover of supplementary insurance from medical care during trips were appropriate. Half of the patients who received the travel medical services did not use supplementary medicine. It can be also mentioned that announcements about supplementary insurance facilities should be improved too. Besides, affording costs and paying them back by the insurance company needs modifications.

\section{Acknowledgments}

We would like to thank all the war survivors and their families for their kind cooperation during this study. Finally we would also like to express our gratitude towards the staff of this center.

\section{Authors' Contributions}

All authors contributed significantly during the study.

\section{Financial Disclosure}

None.

\section{Funding/Support}

None.

\section{References}

1. Bowling A. Research methods in health: investigating health and health services: McGraw-Hill Education (UK); 2014.

2. Habersack M, Luschin G. WHO-definition of health must be enforced by national law: a debate. BMC Med Ethics. 2013;14:24. doi: 10.1186/1472-6939-14-24

3. Tambor M, Pavlova M, Rechel B, Golinowska S, Sowada C, Groot W. Willingness to pay for publicly financed health care services in Central and Eastern Europe: Evidence from six countries based on a contingent valuation method. Soc Sci Med. 2014;116:193-201. doi: 10.1016/j.socscimed.2014.07.009

4. Whorton JC. Inner hygiene: constipation and the pursuit of health in modern society: Oxford University Press, USA; 2000.

5. Weaver KE, Rowland JH, Bellizzi KM, Aziz NM. Forgoing medical care because of cost. Cancer. 2010;116(14):3493-504. doi: 10.1002/cncr.25209

6. Ayoubian A, Tourani S, Dehaghi ZH. Medical tourism attraction of Tehran hospitals. Int J Travel Med Glob Health. 2014;1(2):95-8.

7. Pourkhaghan Z, Faez SEP, Pourkhaghan S, Ghahrieh S. Interaction of economic indicators and medical tourism industry. Int J Travel Med Glob Health. 2014;1(3):133-9.

8. Saravi N, Zaboli R, Hassanzadeh A, Najafipour F, Rezapour A, Rezai-Rad M, et al. Developing Criteria for Complementary Health Insurance (CHI) Benefit Packages for a Medical Service Insurance Organization in Iran: A Qualitative Content Analysis. Int J Travel Med Glob Health. 2015;3(4):171-8.

9. Dercon S. Insurance against poverty: Oxford University Press; 2005.

10. Zargar M, Araghizadeh H, Soroush MR, Khaji A. Iranian casualties during the eight years of Iraq-Iran conflict. Rev Saude Publica. 2007;41(6):1065-6. doi: 10.1590/S0034-89102007000600025

11. Maftoon F, Mousavi B, Mohammad K, Soroush M, Ganjparvar Z. Satisfaction of martyrs' families of supplemental insurance in receiving of paraclinical services. Iran J War Public Health. 2015;7(4):225-32. Persian

12. Aiken LH, Sermeus W, Van den Heede K, Sloane DM, Busse R, McKee M, et al. Patient safety, satisfaction, and quality of hospital 
care: cross sectional surveys of nurses and patients in 12 countries in Europe and the United States. BMJ. 2012;344:e1717.

13. Bell DM, Halliburton JR, Preston JC. An evaluation of anesthesia patient satisfaction instruments. AANA J. 2004;72:211-7.

14. Hertz HS. Baldrige National Quality Program. 2009.

15. Gevers J, Gelissen J, Arts W, Muffels R. Public health care in the balance: exploring popular support for health care systems in the European Union. Int J Soc Welf. 2000;9(4):301-21. doi: 10.1111/1468-2397.00141

16. Bernhart MH, Wiadnyana I, Wihardjo H, Pohan I. Patient satisfaction in developing countries. Soc Sci Med. 1999;48(8):989-96. doi 10.1016/S0277-9536(98)00376-1

17. Al-Abri R, Al-Balushi A. Patient satisfaction survey as a tool towards quality improvement. Oman Med J. 2014;29(1):3-7. doi: 10.5001/omj.2014.02

18. Weisman CS, Rich DE, Rogers J, Crawford KG, Grayson CE, Henderson JT. Gender and patient satisfaction with primary care: tuning in to women in quality measurement. J
Womens Health Gend Based Med. 2000;9(6):657-65. doi: 10.1089/15246090050118189

19. Wright SM, Craig T, Campbell S, Schaefer J, Humble C. Patient satisfaction of female and male users of Veterans Health Administration services. J Gen Intern Med. 2006;21(S3):S26-32. doi: 10.1111/j.1525-1497.2006.00371.x

20. Turris SA. Unpacking the concept of patient satisfaction: a feminist analysis. J Adv Nurs. 2005;50(3):293-8. doi: 10.1111/j.13652648.2005.03392.x

21. Alexander IM. Characteristics of and problems with primary care interactions experienced by an ethnically diverse group of woman. J Am Acad Nurse Pract. 2004;16(7):300-10. doi: 10.1111/j.17457599.2004.tb00453.x

22. Neuberger J. The educated patient: new challenges for the medical profession. J Intern Med. 2000;247(1):6-10. doi: 10.1046/j.13652796.2000.00624.x

23. Swayne LE, Duncan WJ, Ginter PM. Strategic management of health care organizations: John Wiley \& Sons; 2012. 